\title{
Global climate change and cryospheric evolution in China
}

\author{
D. Qin ${ }^{1,2, a}$ and C. Xiao ${ }^{1,3, b}$ \\ 1 State Key Laboratory of Cryospheric Sciences, Cold and Arid Regions and Environmental \\ and Engineering Research Institute, Chinese Academy of Sciences, Lanzhou 730000, China \\ 2 China Meteorology Administration, Beijing 100081, China \\ 3 Chinese Academy of Meteorological Sciences, Beijing 100081, China
}

\begin{abstract}
Major outcomes of Working Group I, IPCC AR4 (2007), as well as the recent understandings from our regional climatic assessments in China were summarized. Changes of cryosphere in China, one of the major components in regional climate system, is specifically reviewed. Under the global/regional warming, all components of cryosphere in China (Tibetan Plateau and surroundings) including glaciers, frozen ground (including permafrost) and snow cover show rapid decay in the last decades. These changes have big socioeconomic impacts in west China, thus encourages both government and scientists pay more and more attention to this field.
\end{abstract}

\section{Global climate change}

"Climate Change 2007: The Physical Science Basis", the Working Group I contribution to the IPCC Fourth Assessment Report (AR4) was launched [4]. IPCC assessment reports summarize peer-reviewed and comprehensive findings from international scientific communities, represent the current level of scientific understanding of global climate change research, and provide an important basis for international climate regime and relevant national policies. The report clearly indicates that the updated recent 100-year warming of the climate system is unequivocal, The most of the observed warming of the climate system over the last 50 years is very likely due to human activities. IPCC AR4 suggests the Arctic is very likely to warm during 21st century in most areas, and the annual mean warming is very likely to exceed the global mean warming. Warming is projected to be largest in winter and smallest in summer. It is likely that the Antarctic will be warmer and that precipitation will increase over the continent.

IPCC AR4 gives the updated understanding of the relationship between past greenhouse gas concentrations and climate. (1) The combined radiative forcing from the three well-mixed greenhouse gases $\left(\mathrm{CO}_{2}, \mathrm{CH}_{4}\right.$ and $\left.\mathrm{N}_{2} \mathrm{O}\right)$ is very likely unprecedented in at least the past $16 \mathrm{kyr}$. Pre-industrial variations of atmospheric greenhouse gas concentrations observed during the last $10 \mathrm{kyr}$ were small compared to industrial era greenhouse gas increases. (2) It is very likely that the current atmospheric concentrations of $\mathrm{CO}_{2}(379 \mathrm{ppm})$ and $\mathrm{CH}_{4}(1,774 \mathrm{ppb})$ exceed by far the natural range of the last $650 \mathrm{kyr}$. Ice core data indicate that $\mathrm{CO}_{2}$ varied within a range of 180 to $300 \mathrm{ppm}$ and $\mathrm{CH}_{4}$ within 320 to $790 \mathrm{ppb}$ over this period. Over the same period, Antarctic temperature and $\mathrm{CO}_{2}$ concentrations co-vary, indicating a close relationship between climate and the carbon cycle. (3) It is very likely that glacial-interglacial $\mathrm{CO}_{2}$ variations have strongly amplified climate variations, but it is unlikely that $\mathrm{CO}_{2}$ variations have triggered the end of

\footnotetext{
a e-mail: qdh@cma.gov.cn

b e-mail: cdxiao@lzb.ac.cn
}

Article published by EDP Sciences and available at http://www.epj-conferences.org

or http://dx.doi.org/10.1140/epjconf/e2009-00907-x 
glacial periods. Antarctic temperature started to rise several centuries before atmospheric $\mathrm{CO}_{2}$ during past glacial terminations. (4) It is likely that earlier periods with higher than present atmospheric $\mathrm{CO}_{2}$ concentrations were warmer than present. This is the case both for climate states over millions of years (e.g., in the Pliocene, about 5 to $3 \mathrm{Ma}$ ) and for warm events lasting a few hundred thousand years (i.e., the Palaeocene-Eocene Thermal Maximum, $55 \mathrm{Ma}$ ). In each of these two cases, warming was likely strongly amplified at high northern latitudes relative to lower latitudes.

IPCC AR4 emphases the feedback, biogeochemical and biogeophysical processes in palaeoclimatic records. (1) There is positive amplification of global climate system to orbital forcing. This amplification has very likely been influenced mainly by changes in greenhouse gas concentrations and ice sheet growth and decay, but also by ocean circulation and sea ice changes, biophysical feedbacks and aerosol (dust) loading. (2) It is virtually certain that millennialscale changes in atmospheric $\mathrm{CO}_{2}$ associated with individual Antarctic warm events were less than $25 \mathrm{ppm}$ during the last glacial period. This suggests that the associated changes in North Atlantic Deep Water formation and in the large-scale deposition of wind-borne iron in the Southern Ocean had limited impact on $\mathrm{CO}_{2}$. (3) It is very likely that marine carbon cycle processes were primarily responsible for the glacial-interglacial $\mathrm{CO}_{2}$ variations. The quantification of individual marine processes remains a difficult problem. (4) Palaeoenvironmental data indicate that regional vegetation composition and structure are very likely sensitive to climate change, and in some cases can respond to climate change within decades.

\section{Climate changes in China}

\subsection{Last 2000 years}

The climate has fluctuated during the last 2000 years, while overall temperature gradually decreased except for the last 100 years. There were at least four warm periods, 1-209AD, 570-779AD, 930-1319AD (Medieval Warm Period, MWP) and 1920AD to the present; and three cold periods, 210-569AD, 780-929AD and 1320-1919AD (Little Ice Age, LIA). Temperatures in the warm (cold) periods were $0.5-1.0^{\circ} \mathrm{C}$ above $\left(1.0^{\circ} \mathrm{C}\right.$ below) the normal. Precipitation varied in the last 2000 years independently of temperature changes. During the 2nd to 11th centuries, it was dry in western China and wet in eastern China. During the 16th to 19th centuries, it was dry in northern China and wet in southern China. Moreover, there was a predominant 80 to 100 -year period in precipitation change, with the 20 to 30 -year interdecadal variability and 2 to 4 -year interannual variability overlapped. Climate change in western China differed from that in eastern China during the last 2000 years. For example, the features of the MWP could be seen more clearly in eastern China than that in western China. Also, it was especially cold in the LIA in eastern China.

\subsection{Last 100 years}

Present climate warming is a hot topic in climate change studies. The warming rate was $0.81^{\circ} \mathrm{C} / 100$ a according to instrumental observations of the maximum and minimum temperatures mainly over East China. However, it was $0.58^{\circ} \mathrm{C} / 100$ a based on the instrumental observations of daily mean temperatures blended with proxy data, especially in western China. It can be concluded that the warming in China was about at a range of $0.5-0.8^{\circ} \mathrm{C} / 100 \mathrm{a}$, although it varies from author to author due to different data sources and techniques used in their analyses. In the past 100 years there were two warming periods, 1920s-1940s and the period from 1980 to the present. No trend was found in precipitation change for the last 100 years, but 20 to 30 -year variability predominated over eastern China. The pattern of summer rainfall changed in the late 1970s, i.e., from floods in northern China and drought in southern China to drought in northern China and floods in southern China. In western China, especially in Xinjiang region, precipitation significantly increased during the last 20 years. 

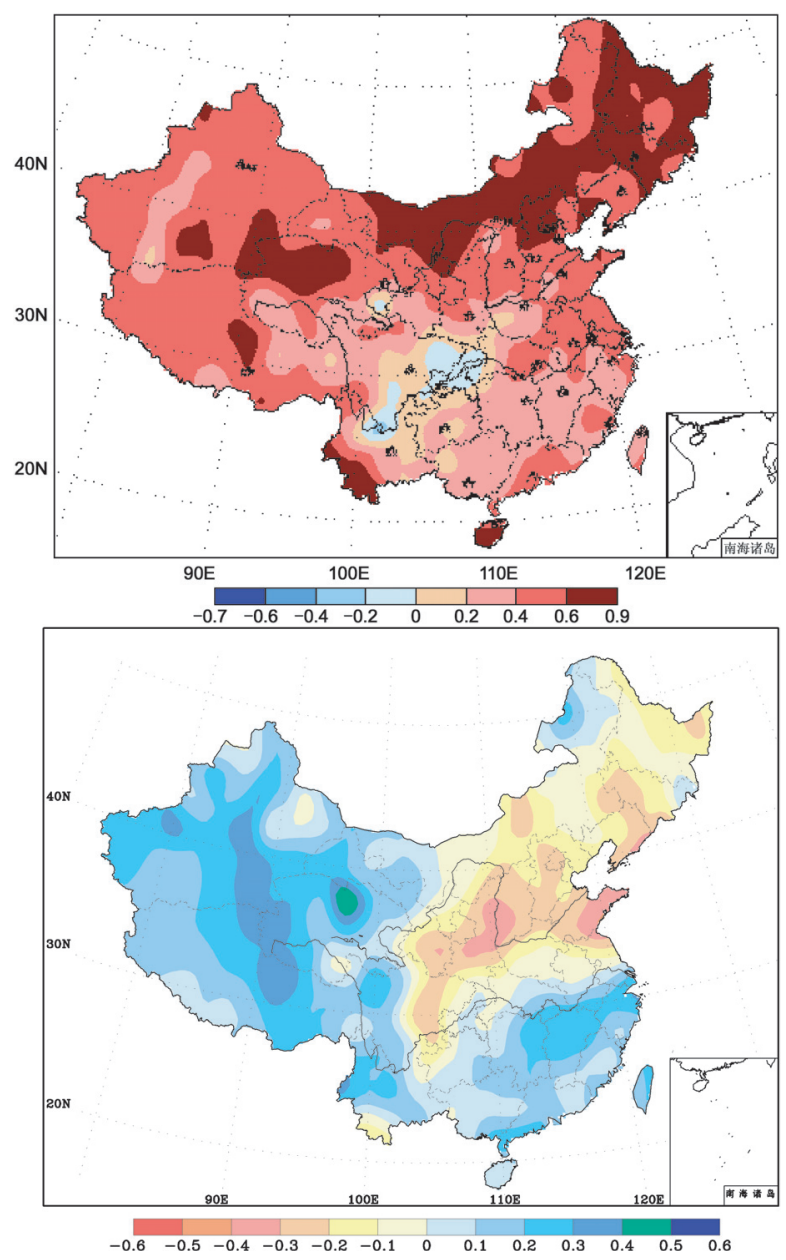

Fig. 1. Spatial distribution of temperature (a) and precipitation (b) changes $\left({ }^{\circ} \mathrm{C}\right.$ and percentages: 0.6 means $60 \%$ of precipitation change) over China during 1951-2000AD (based on NCC, CMA).

\subsection{Last 50 years}

In the last 50 years, the increase of annual mean temperature was mainly observed over northern China. The increase rate of temperature in northern part of Northeast China, Inner Mongolia and the basins of western China is more than $0.8^{\circ} \mathrm{C} / 10 \mathrm{a}$, which indicates an increase of more than $4{ }^{\circ} \mathrm{C}$ in the last 50 years in these regions (Figure 1). The most prominent increase in precipitation amount was seen in the basins of western China, with the greatest increase $10 \%^{-}$ $15 \% / 10 \mathrm{a}$, which indicates that the precipitation amount in these regions has increased by $50 \%-75 \%$ in the last 50 years, while in North China and south of Northeast China, the changes in precipitation amount have shown a decreasing trend.

\subsection{Projection for the 21st century}

Under the scenarios with different emissions of greenhouse gases and aerosols, the climate change of future 100 years in China are projected based on the global and regional climate models developed in China and the data from IPCC Data Distribution Center. About 40 climate models project that, due to the impacts of human activities, the prominent warming in China will continue, especially over northern China in winter. Compared with the average of $1961-1990$, the nationwide annual mean temperature will increase by $1.3-2.1^{\circ} \mathrm{C}$ in 2020 , by 


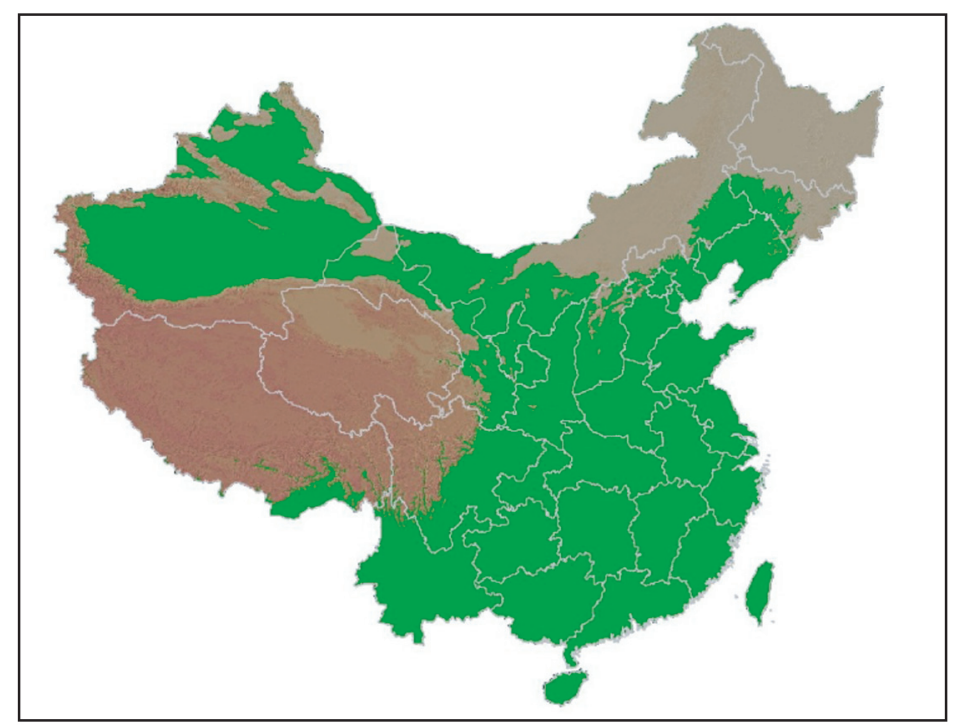

Fig. 2. Distribution of cold regions in China [1].

$1.5-2.8^{\circ} \mathrm{C}$ in 2030 , by $2.3-3.3^{\circ} \mathrm{C}$ in 2050 and by $3.9-6.0^{\circ} \mathrm{C}$ in 2100 . Both daily maximum and minimum temperatures will be rising, but the latter will raise more, resulting in the decrease of daily temperature range [8].

The annual mean precipitation in China will increase by $2 \%-3 \%$ in 2020 , by $5 \%-7 \%$ in 2050 , by $7 \%-9 \%$ in 2070 , by $11 \%-17 \%$ in 2100 , with differences among regions. In Northwest China, Northeast China and South China, precipitation will increase by $10 \%-25 \%$. However, in the regions along the Bohai Sea Coast and the Yangtze River Delta, it will become dry. The number of rainy days will increase in northern China, and the number of heavy rainy days will increase in southern China resulting from the possible increase in local heavy rainfall events.

\section{Climate changes in cryospheric regions of China}

Cryospheric in China is one of the major parts of cold regions in the low to mid-latitudes. Cold region has been widely used. However, there is no standard definition for it. The cold regions in China include all the permafrost areas, all the glacier areas, and by far the majority of stable seasonal snow cover. Using temperature records from 571 meteorological stations in China, [1] defined 'cold regions' in China as, the averaged air temperature in the coldest month was less than $-3.0^{\circ} \mathrm{C}$, the number of month in which the averaged air temperature was higher than $10^{\circ} \mathrm{C}$ was not more than 5 , and the averaged yearly temperature was not more than $5.0^{\circ} \mathrm{C}$. The boundary and distribution of the partition were accordant to those of permafrost, glaciers, snow cover, vegetation distribution and climate regionalization. According to the above definition the area of 'cold regions' in China is about $417.4 \times 10^{4} \mathrm{~km}^{2}$, which is $43.5 \%$ of the land area in China.

Based on the Qamdo tree-ring $\delta^{13} \mathrm{C}$, the Dasuopu ice core $\delta^{18} \mathrm{O}$ and previous composite temperature reconstruction for the Tibetan Plateau, together with other types of proxy data, [16] made an analysis of temperature change on the Tibetan Plateau during the last millennium. This work provides a basis for further integrated study of climate change. The following conclusions were drawn: (1) There exist correlative periods for the MWP and LIA on the Tibetan Plateau, which occurred in 1200-1400 AD and 1400-1700 AD, respectively. (2) Average summer temperature on the Tibetan Plateau during the MWP was up to $1.2{ }^{\circ} \mathrm{C}$ higher than at present. The warmest period during the past 1000 years occurred in the 13 th century, when summer temperature was $1.6{ }^{\circ} \mathrm{C}$ higher than at present. (3) Average summer 

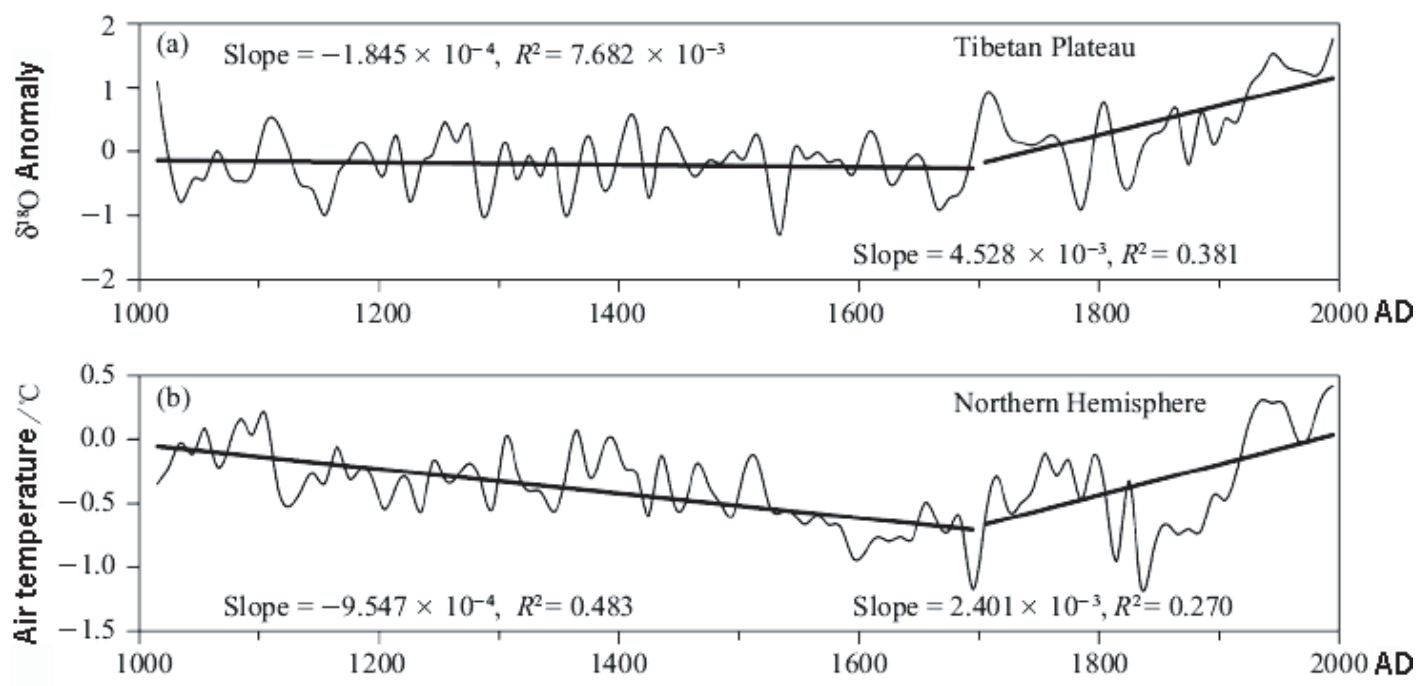

Fig. 3. Comparison of temperature variation between the Northern Hemisphere [5] and Tibetan Plateau [17].

temperature on the Tibetan Plateau during the LIA was about $0.5^{\circ} \mathrm{C}$ lower than at present. The coldest period of the last millennium occurred during 1000-1200C AD, when summer temperature in the Qamdo region was about $1.5^{\circ} \mathrm{C}$ lower than at present. (4) The 20th warming on the Tibetan Plateau is mainly attributable to the rising winter temperature, whereas summer temperature shows a slight decreasing trend.

Ref. [17] reconstructed decadal variations of temperature in Tibetan Plateau based on the four ice core $\delta^{18} \mathrm{O}$ records. The four ice cores are respectively drilled at Puruogangri (central plateau), Guliya (western plateau), Dasuopu (southern plateau) and Dunde (northern plateau). Although temperatures varied from site to site, all curves display increasing trends overall. The composite curve (Figure 3) can be considered as presenting high altitudes climate in Tibetan Plateau (elevation higher than $5500 \mathrm{~m}$ a.s.l.). The overall characteristics of the climate were (1) warming of the MWP ended until 13th century, 3 relative warming and 3 relative cooling periods were detected. (2) The 14th and 16th centuries were relatively cold. (3) The 15th and 17 th centuries were relatively warm. (4) From the end of 17 th century to 1920 's, there were high fluctuations of temperature, when-after the temperature increases and continues to the present. The recent warm period is the highest in the last 1000 years. (5) The overall trend is similar between Tibetan Plateau and North Hemisphere trend by [5].

\section{Cryospheric changes in China}

The cryosphere in China is mainly located in the Tibetan Plateau, the eastern Tien Shan, the Altai Shan, the east Pamirs and the northeast China. The total number of glaciers in China is 46298 , with a total area of $59406 \mathrm{~km}^{2}$ and an ice volume of $5590 \mathrm{~km}^{3}$. The permafrost and the seasonally frozen ground (SFG) cover an area of $1.49 \times 10^{6}$ and $5.28 \times 10^{6} \mathrm{~km}^{2}$, accounting for $11.5 \%$ and $55 \%$ of Chinese land territory, respectively. The snow-covered area in China is around $9.0 \times 10^{6} \mathrm{~km}^{2}$, and of this an area over $4.8 \times 10^{6} \mathrm{~km}^{2}$ consists of unstable snow cover (duration $<20$ days). Stable snow cover (duration $>60$ days) is mainly located in the Tibetan Plateau, north Xinjiang (including the Tien Shan) and the Inner Mongolia-northeast China (hereafter IM-NEC) regions. The mean snow-cover areas of these three regions are $2.3 \times 10^{6}$, $0.5 \times 10^{6}$ and $1.4 \times 10^{6} \mathrm{~km}^{2}$, respectively. Seasonal sea ice forms in the Bohai Sea and in the northern Yellow Sea of China. Sea ice forms in mid- to late November, reaches its maximum area in late January to early February and melts away in late March. River ice forms in most rivers in north China, including the Yellow, Songhuajiang, Nengjiang and Liaohe rivers. 


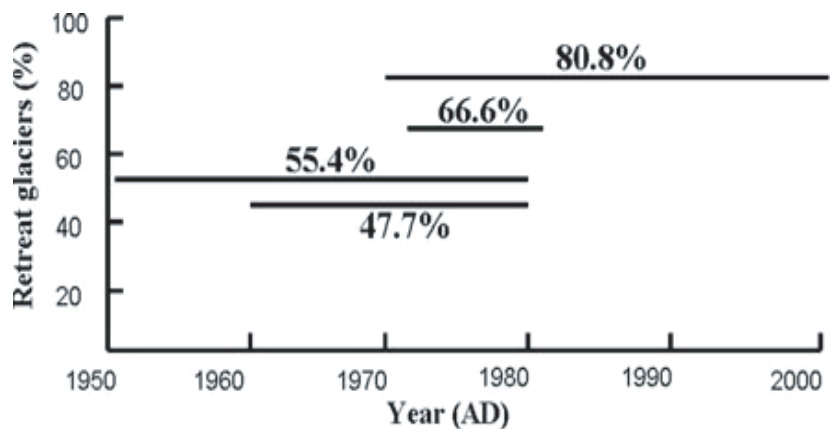

Fig. 4. Percentages of retreating glaciers among a total of 764 glaciers in China during the past five decades [18].

There are few reliable observations available for the cryosphere before 1949, when the People's Republic of China was established, but since then glaciers and frozen ground over the Tibetan Plateau and Tien Shan have been widely investigated. Since 1951, snow cover has been measured at meteorological station networks governed by the China Meteorological Administration. Sea- and river-ice observations were also started in the 1950s. These observations give an insight into regional climate change over the past half-century. However, most of the data were published in Chinese, and thus unknown to international communities. Presently, the Chinese National Committee of the World Climate Research Program (WCRP)/Climate and Cryosphere Project (CliC) (CliC-CNC) is working on synthesizing cryospheric data. Here, we review these results, based mostly on direct observations and partly on remote-sensing methods, which can certainly contribute to an overall assessment of the present and future state of the global cryosphere.

The general understanding of the cryospheric changes in China in the last 50 years of the 20th century include the follow.

\section{(1) Glaciers}

Sporadic field investigations in the past few decades show that changes of glacier lengths vary in different areas. The breadth of these changes varies because of different climatic conditions, glacier sizes and facings. Relatively small changes were found in the Qilian Shan and in the central Tibetan Plateau and in some large glaciers in the Himalaya. We define the changes of $<500 \mathrm{~m}$ between the 1950's and 2000 as a small retreat. Large retreats are occurring on glaciers in the margins of the QXP, the Pamirs and the western Tianshan. Between the 1950's and 2000, the glacier retreated $>500 \mathrm{~m}$. Although retreat is the overwhelming trend, some glaciers in the central and southeastern Tibetan Plateau are still advancing. This is probably due to the response of the glaciers to the present cooling of the local climate [11], or due to enhanced transport of moisture to high altitudes $[3,7]$.

Glacier changes for 764 glaciers in western China were studied using digital photos from Landsat TM/ETM+ and Terra ASTER. The changes have varied remarkably in different regions. In total, about $80.8 \%$ of the studied glaciers are retreating or have vanished, while $19.2 \%$ are advancing (Figure 4). For each region (mountain range), the number of advancing glaciers is much less than that of retreating glaciers. The percentage of advancing glaciers on the margin of the QXP (e.g. Qilian, A'nyê̂aqen and Qomolangma) is higher than in the interior. Because of the resolution limits of the photos, changes of some small glaciers and some stable glaciers cannot be determined; this should be considered when assessing the overall changes of glaciers.

Based on the above observations and the typical glacier monitoring, [18] estimated a shrinkage of $3790 \mathrm{~km}^{2}$ of glacier areas in approximately the past 40 years, which equals a mean glacier thinning rate of around $0.2 \mathrm{~m} \mathrm{a}^{-1}$.

(2) Snow cover

Annual variations of snow cover in the three major snowcover regions (Xinjiang, Tibetan Plateau and Inner Mongolia-North East China (IM-NEC)) were studied based on station observations. 


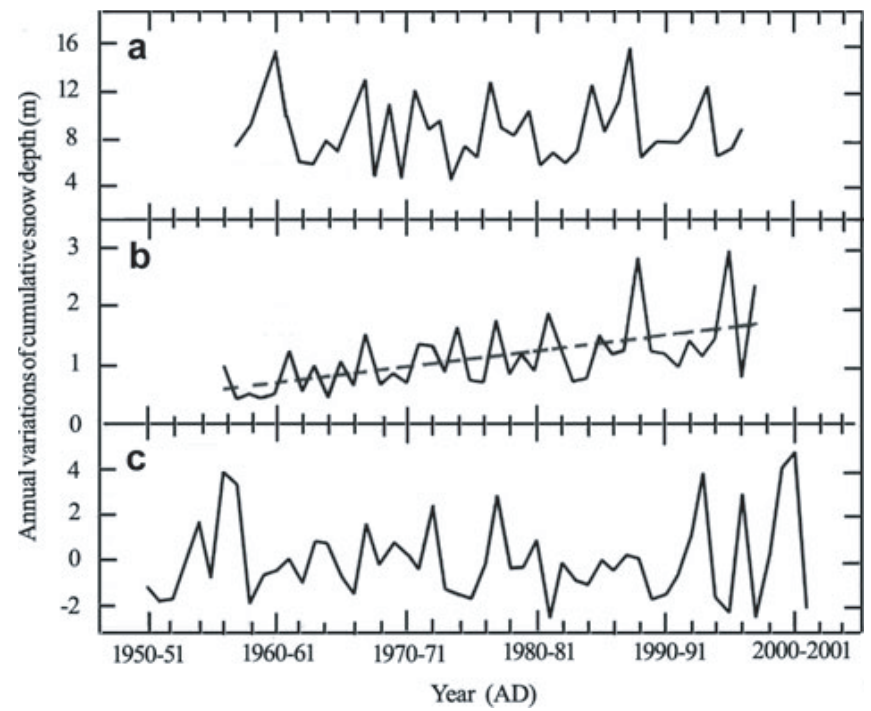

Fig. 5. Interannual variability of snow cover over China during the past 50 years: (a) Xinjiang, (b) Tibetan and (c) IM-NEC region [9].

For the Xinjiang and IM-NEC regions, the results of ground observation coincide with those derived from SMMR-Special Sensor Microwave/Imager (SSM/I), but for the Tibetan Plateau there are biases because of insufficient station data over the plateau. Figure 5a shows a time series of the annual and spring ablation season (March and April), number of days with snow cover, and annual cumulative daily snow-cover depth over northwest China from 1951 through 1997. It demonstrates that long-term variability of snow cover is normally characterized by random oscillation. Snow cover fluctuated around the mean, alternating between heavy and light snow cover. Neither abrupt changes nor continuation of snow minima from the late 1980s and early disappearance of spring snow cover were found.

From the end of the 1980s, however, a prolonged decrease in snow cover was seen, but not as great as the three previous snow-deficit periods. In the 1960s and early 1970s, measured snow cover was lower than at any other time in the second half of the 20th century.

Over the Tibetan Plateau, long-term variability of snow cover is characterized by large interannual variabilities superimposed on a continuous increasing trend. Furthermore, the annual amplitude of snow-cover variability has increased significantly since the 1980s (Fig. $5 b)$. Both extremely heavy and light snow-cover years occurred more frequently. The anomalies did not appear to be outside the range of natural variability.

In the IM-NEC region, there are several scattered areas with deep snow cover where large interannual variabilities in snow depth were observed. These areas include the DaHinggan, the Xiao Hinggan and Xilinguole. There are also large seasonal variations in snow depth. The deepest snow cover appears in mid-winter, when the largest interannual snow depth variations also occur. The overall trend in the IM-NEC regions shows a very slight decrease $\left(0.1 \mathrm{~m} \mathrm{a}^{-1}\right)$ in snow depth (Fig. 5c).

The annual snow-cover variations depend both on the amount of winter snowfall and on the winter temperatures. Ref. [6] established relationships between snow cover and winter air temperatures and precipitation, respectively for the Xinijing, Tibetan Plateau and IM-NEC regions. They are:
Xinjiang:
$\mathrm{Sd}=20: 86 \mathrm{P}-150: 39 \mathrm{~T}-738.8$
$\mathrm{Sn}=0: 48 \mathrm{P}-4: 51 \mathrm{~T}-35.2$
Tibetan Plateau:
$\mathrm{Sd}=1: 99 \mathrm{P}-14: 21 \mathrm{~T}-121.1$
IM-NEC:
$\mathrm{Sd}=11: 95 \mathrm{P}-43: 2 \mathrm{~T}-279$ 


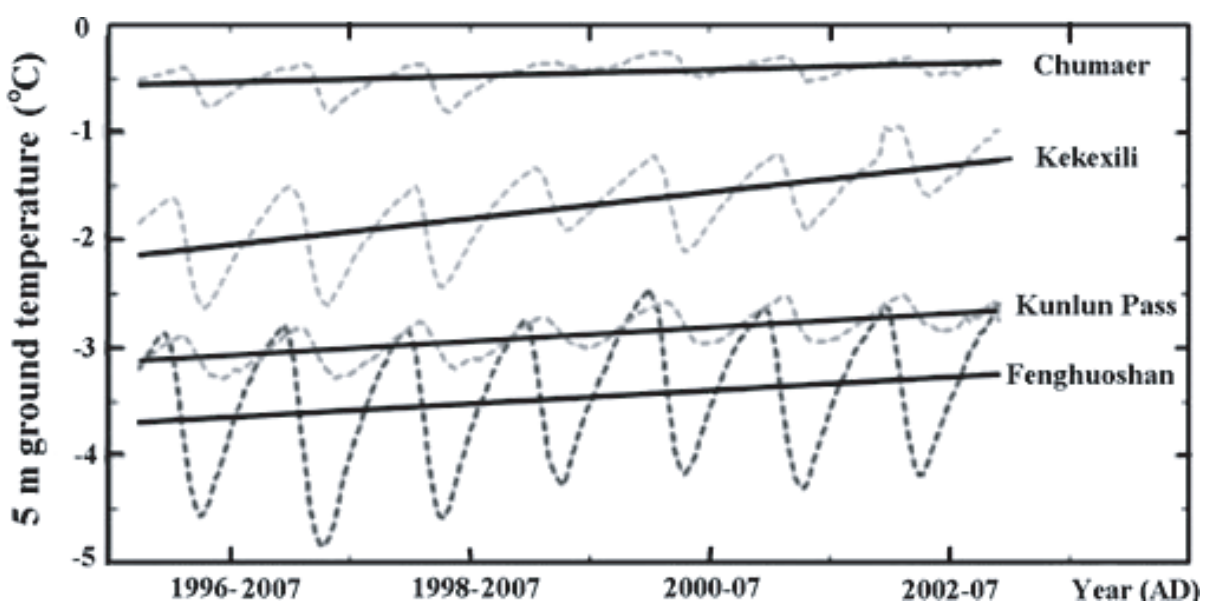

Fig. 6. Ground temperature variation at $5 \mathrm{~m}$ depth below natural surface along Tibetan highway since $1995[14]$.

Sd and Sn are the annual daily cumulative snow depth data $(\mathrm{cm})$ and annual number of snowcover days, respectively, $\mathrm{P}$ is the amount of winter snowfall $(\mathrm{mm})$ and $\mathrm{T}$ is the mean air temperature during the snow-cover season.

The interannual snow-cover variations based on the above functions coincide well with the observed results, with an error range within $\pm 10 \%$. However, these functions cannot properly reproduce long-term changes in snow cover, probably due to the large errors in measuring solid precipitation.

(3) Permafrost and seasonal frozen ground

According to [19], permafrost temperatures over the hinterland of the Tibetan Plateau increased by about $0.20-0.58^{\circ} \mathrm{C}$ between the 1970 s and the $1990 \mathrm{~s}$. Permafrost temperatures were measured at four sites along the northern section of the Qinghai-Xizang (Tibetan) highway: Chumaer river, Kekexili, Kunlun Pass and Fenghuoshan (Figure 6). At these sites, ground temperature at $5 \mathrm{~m}$ depth was averaged to have increased up to $0.58^{\circ} \mathrm{C}$ cover the period $1995-2002[14,20]$. Permafrost temperatures increased by about $0.2-0.48^{\circ} \mathrm{C}$ from 1973 to 2002 at $16-20 \mathrm{~m}$ depths in the Tien Shan region $[10,20]$. Permafrost surface temperatures increased by about $0.7-1.58^{\circ} \mathrm{C}$ over the period 1978-91 from the valley bottom to the north-facing slopes in the Da Hinggan Ling in northeastern China (Zhou and others, 1996). Permafrost temperature at the depth of the zero annual temperature variation increased by about $2.18^{\circ} \mathrm{C}$ on the valley bottom, $0.78^{\circ} \mathrm{C}$ on the north-facing slopes and $0.88^{\circ} \mathrm{C}$ on the south-facing slopes. The active layer increased by about $40 \mathrm{~cm}$ at Jiagedaqi over permafrost, from an average of $240 \mathrm{~cm}$ in the $1960 \mathrm{~s}$ to an average of $280 \mathrm{~cm}$ in the 1990s (Liu and others, 2003).

Over the Tibetan Plateau, the seasonal frozen ground (SFG) thickness decreased over a range $0.05-0.22 \mathrm{~m}$ from 1967 through 1997 [20]. The driving force for the decrease was the significant warming in cold seasons, while changes in snow-cover depth played a minor role. The duration of SFG shortened by > 20 days from 1967 through 1997, mainly due to the earlier onset of thaw in spring rather than the late onset of freeze in autumn.

The average and maximum SFG depths and the duration of the frost period at $10 \mathrm{~cm}$ depth in Xinjiang during the period 1961-2002 are analyzed by [13]. The results show that the average and maximum depths of the freezing front and the duration of the frost period are decreasing due to warmer climate in Xinjiang in recent decades. Such changes have become more significant since 1986, after an obvious shift of local climate towards a warmer, wetter regime. Significant decrease of the maximum depths reached by the freezing front occurred in the mid-1980s, both in south and north Xinjiang (Figure 7).

Data on the upper and lower limits of SFG, as well as on the duration of the frost period, collected from 17 meteorological stations in the Hexi Corridor in the period 1958-2003 show a rapid decrease in the depth reached by the freezing front in the mid-1980s. This coincides 


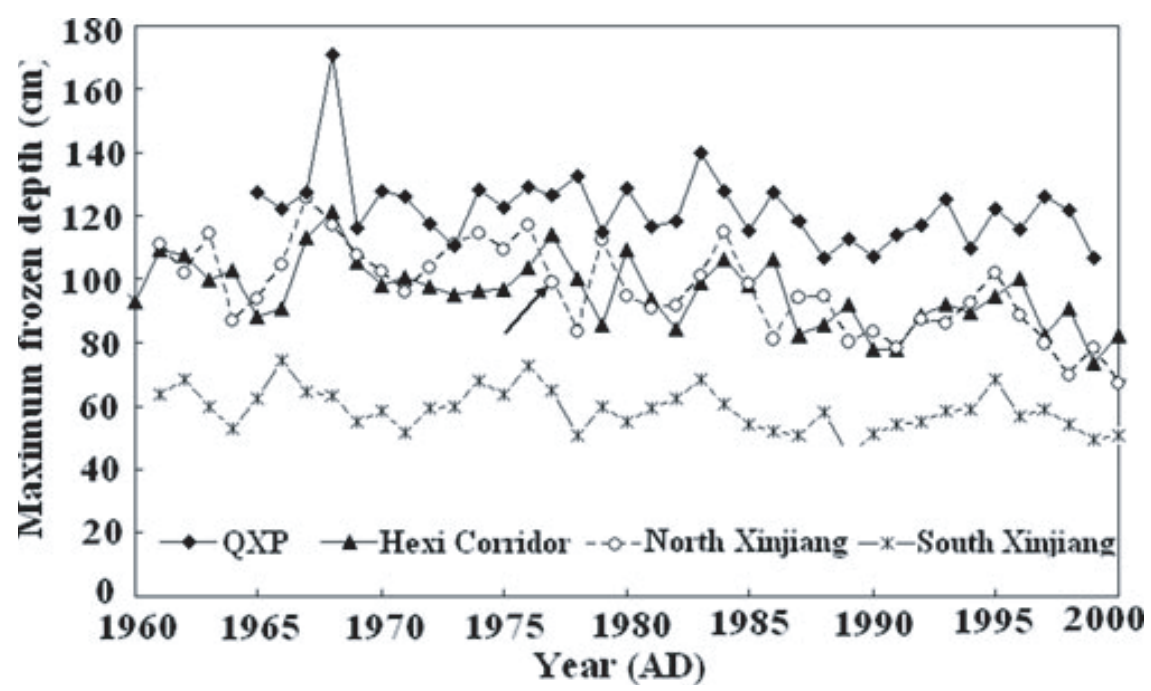

Fig. 7. Changes in maximum frozen depths of the seasonally frozen ground over the Tibetan Plateau, Hexi Corridor and Xinjiang [15].

with an increase in winter temperature over the same period. The minimum air temperature in winter controls the maximum depth reached by the freezing front and the duration of the frost period [2].

In northeast China, there are few SFG studies, but since an obvious trend of increased air temperatures has been observed for the past 50 years, it is clear there has been a reduction of SFG. Observations show a rapid increase of winter air temperature in northeast China in the past five decades [12], which is harmful to the preservation of SFG.

(4) Other cryospheric components

Sea-ice areas in the Bohai and north Yellow Seas have been shrinking since the 1970s. Interannual variations possibly relate to the solar cycles, and sea-ice extent extremes relate to El Ninô-Southern Oscillation (ENSO) events. The freeze-up and break-up dates of river ice in north China in the 1990s are, on average, 1-6 days later and 1-3 days earlier, respectively, than the 1950s-1990 mean. Frozen duration and the maximum thickness of river ice are, respectively, $4 \sim 10$ days shorter and $0.06 \sim 0.21 \mathrm{~cm}$ thinner in the $1990 \mathrm{~s}$ than the average [15].

Solid precipitation, including the number of days with frost and hail storms, shows a decreasing tendency over the past 50 years.

\section{Conclusion and perspectives}

Global data evidences the 20th century's warming is unequivocal. Studies in China show that the regional warming in the last century was also robust. The temperature trends in China were in coincidence with that global and hemispheric averages in the millennial and centurial scales. Future climate in China under IPCC scenarios will increase $1.3-6.0^{\circ} \mathrm{C}$ in the 21 st century. Most components of cryosphere including glaciers, frozen ground and snow cover displayed decay trends in the last century, especially in the latest 50 years. In the future, cryospheric decay will continue and may response the faster warming. This will be extremely danger to the arid and semi-arid regions in west China, where people depends on the melting waters from the high mountain glaciers/frozen ground/snow cover.

Chinese government is paying more and more attention to the cryospheric changes in China. Supported by the by the Ministry of Science and Technology of China (MoST), National Natural Science Foundation of China (NSFC), Chinese Academy of Sciences (CAS), China Meteorological Administration (CMA), as well as bilateral cooperation sources, cryospheric studies were 
much strengthened in recent years in China. The relevant studies are valuable to policymakers for socio-economic assessments and management.

The authors are grateful to the invitation of ERCA course and discussion with all students. This research is funded by IPCC, the Ministry of Science and Technology of China (MoST) (2007CB411500; 2005DFA20930) and the Climate Project of the China Meteorological Administration.

\section{References}

1. R. Chen, E. Kang, L. Wu, et al., J. Glaciol. Geocryol. 27, 470 (2005) (in Chinese)

2. H. Guo, D. Li, Q. Zhang, D. Lu, J. Fen, J. Qing, M. Tang, Z. Zhen, J. Glaciol. Geocryol. 27, 503 (2005) (in Chinese)

3. K. Hewitt, Mount. Res. Dev. 25, 332 (2005)

4. IPCC, 2007: Contribution of Working Group I to the Fourth Assessment Report of the Intergovernmental Panel on Climate Change, edited by S. Solomon, D. Qin, M. Manning, Z. Chen, M. Marquis, K.B. Averyt, M. Tignor, H.L. Miller (Cambridge University Press, Cambridge, NY, USA, 2007), p. 996

5. P.D. Jones, T.J. Osborn, K.R. Briffa, Science 292, 662 (2001)

6. P. Li, Distribution, Glaciers and Related Environments in China - The Past, Present and the Future, edited by Y. Shi (Science Press, Beijing, 2000), p. 101 (in Chinese)

7. S. Liu, et al., Ann. Glaciol. 43, 187 (2006)

8. D. Qin, Y. Ding, J. Su, et al., Adv. Clim. Change Res. 2, 1 (2006a)

9. D. Qin, S. Liu, P. Li, J. Clim. 19, 1820 (2006b)

10. G. Qiu, Y. Zhou, D. Guo, Frozen ground in Northwest China, edited by Y. Zhou, D. Guo, G. Qiu, G. Cheng, S. Li (Beijing, Science Press, 2000), p. 220 (in Chinese)

11. Y. Shi, S. Liu, D. Shangguan, D. Li, B. Ye, Ann. Glaciol. 43, 106 (2006)

12. F. Sun, J. Yuan, Adv. Climate Change Res. 1, 168 (2005) (in Chinese)

13. S. Wang, R. Wu, X. Yang, Climate change in China, edited by D. Qin, Y. Chen, X. Li, Y. Ding, Y. Ding, Vol. 1 (Beijing, Science Press, 2005), p. 63 (in Chinese)

14. Q. Wu, Y. Liu, Cold Regions Sci. Technol. 38, 85 (2004)

15. C. Xiao, S. Liu, L. Zhao, et al., Ann. Glaciol. 46, 382 (2007)

16. B. Yang, A. Brraining, Y. Shi, Quatern. Sci. Rev. 22, 2335 (2003)

17. T. Yao, D. Qin, B. Xu, et al., Adv. Clim. Change Res. 2, 99 (2006) (in Chinese)

18. T. Yao, Y. Wang, S. Liu, J. Pu, Y. Shen, A. Lu, Sci. China D 47, 1065 (2004)

19. L. Zhao, G. Cheng, S. Li, Changes of plateau frozen ground and environmental engineering effects, edited by D. Zheng (Hebei Science and Technology Press, 2003), p. 143 (in Chinese)

20. L. Zhao, C. Ping, Y. Daqing, G. Cheng, Y. Ding, S. Liu, Global Planet. Change 43, 19 (2004) 